\section{The pork-barrel diet}

\author{
What to Eat: An Aisle-by-Aisle Guide to \\ Savvy Food Choices and Good Eating \\ by Marion Nestle \\ North Point Press: 2006.624 pp. \$30
}

\section{Tim Lang}

What to Eat is based around a simple idea: how to choose our weekly shopping from the stacked shelves of the average supermarket to achieve a healthy diet. Shopping, like walking or breathing, is deceptively simple. We do it naturally until something happens to make us realize it is both complex and astonishing. In a world where thousands of messages urge us to eat this or drink that, where most supermarkets stock up to 30,000 items, and where value-for-money can drown out value-forhealth, choosing the right food to keep our bodies healthy has become very complex.

When Clarence Saunders opened the first self-service grocery store in Memphis, Tennessee, in 1916 he had no idea that persuading consumers to act as shop assistants would instigate a world-wide cultural revolution. Huge savings were achieved, and power relations across the food-supply chain were restructured. Not without reason are the modern supermarket giants such as Wal-Mart, Tesco, Ahold and Carrefour treated with awe in management circles. Their logistics and ruthless supply-chain management keep the shelves full. The humble shopkeepers of old have become today's key gatekeepers of consumerism.

If the restructuring of the food economy is the background to Marion Nestle's excellent new book, the immediate problem she sets out to resolve is how to balance supermarket shopguide. A leading US public-health nutritionist with a long and honourable track record of standing up for the public in the sometimes heated world of American food and health politics, she has the advantage of having worked inside government. She was a key player in the US surgeon general's 1988 Report on Nutrition and Health, and has seen at first hand the sometimes surreal high-level negotiations behind the lofty aspirations for evidence-based policy - something she explored in her two previous books, Food Politics (University of California Press, 2002) and Safe Food (University of California Press, 2003).

Like other areas of science, nutrition is framed by political realities. Whose interests are being served? Will this or that power bloc be affected if we tell people to cut down on sugar or meat? In a world where food is very big money, and where nigh on a billion starve while a billion overeat, we are seeing a bizarre globalization of 'pork-barrel politics' in which particular constituencies benefit while ping and good health. Nestle makes a superb everyone pays. Land that should be producing food for health is producing food for wealth.

This wider context is germaine to Nestle's book. How, she asks, can the informed consumer make sense of health demands in an overconsuming, warped food culture? She gives her answers in a walk round a virtual American supermarket, always drawing on real foods and real situations. I imagine her doing this with a trail of enquiring, questioning consumers in a modern socratic food dialogue. "See this food that's been presented as wholesome, good for a healthy heart or endorsed by science? Well, it's not that simple..."

Starting with fruit and vegetables (which usually greet us to remind us we are in a food shop, not just another store in the mall), then progressing to dairy, dairy substitutes, meat, fish, convenience and frozen foods, processed foods, beverages and soft drinks, breads and finally specialities such as baby foods, she stops us and asks: which food would you buy? And then she gives us the data to inform our choice.

On eggs, for example, she unravels the hyperbole around omega-3 fatty acids now being put (via feed) into eggs to counteract their association with cholesterol. After unpicking the complexities of whether high-cholesterol foods automatically lead to high cholesterol in the consumer (it all depends, but they don't help), she boils it down to advice to eat no more than one egg a day, and if you eat that one, avoid other foods made with eggs and other highcholesterol foods. The book is full of such conclusions: she never spares the intricacies, but always brings us to a point where we can make choices about whether to buy.

On the complex issue of fish, Nestle teases apart the nutritional profiles according to method of production, and shows how she personally juggles the various demands on the informed consumer. She considers the nutrients of different fish, safety and contamination issues, whether they are farmed or wild, processed or fresh, coloured or natural. Today, even bread is made with fish oils. As she says, "I prefer fish as a source of omega-3s." Me too.

In exasperation at not easily being able to health-enhancing, safe, environmentally benign, affordable, trustworthy food - she sometimes reminds us that there can be no individualized solution to this juggling of ethics, science, health and the market. Her answer, given in a purple passage, lies in advocacy to reframe the 'rules of engagement' in the ongoing food war.

Gradually, governments, the wider public and some thinkers at various points in the food chain are realizing that the policy mix is failing. Health education doesn't work. Excess consumer choice is part of the problem. Developing countries are sleepwalking into Western eating lifestyles. Obesity is rampant. Health bills are rocketing, threatening rich as well as poor countries. Our current mode of eating is also ecologically damaging.

Books like this are so important in keeping that bigger picture before the policy-makers. Dare we even think that, one day, the supermarket chains might stop selling unnecessary food? While we are exhorted to eat less, they keep on selling more.

Tim Lang is at the Centre for Food Policy, City University, Northampton Square,

London EC1 OHB, UK. get what any decent consumer would want -

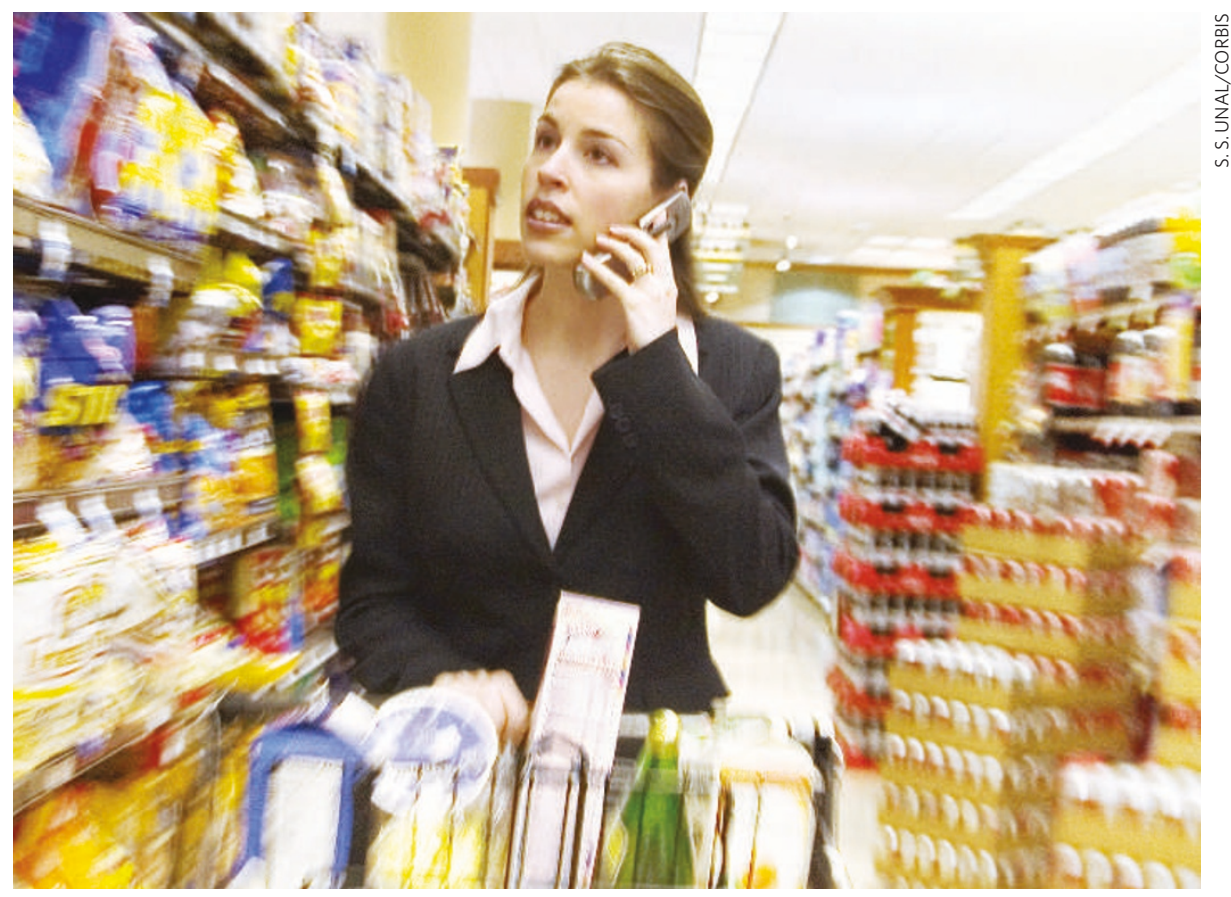

Asking for help: consumers are faced with an array of difficult choices about which food is healthiest. 